\title{
Radicava/Edaravone Findings in Biomarkers From Amyotrophic Lateral Sclerosis (REFINE-ALS)
}

\author{
Protocol and Study Design
}

James Berry, MD, Benjamin Brooks, MD, Angela Genge, MD, Terry Heiman-Patterson, MD, Stanley Appel, MD, Michael Benatar, MD, PhD, Robert Bowser, PhD, Merit Cudkowicz, MD, Clifton Gooch, MD, Jeremy Shefner, MD, PhD, Jurjen Westra, PhD, Wendy Agnese, PharmD, Charlotte Merrill, PhD, MBA, Sally Nelson, MS, PhD, and Stephen Apple, MD

Correspondence

Dr. Apple

stephen_apple@mt-pharma-us.com

Neurology: Clinical Practice August 2021 vol. 11 no. 4 e472-e479 doi:10.1212/CPJ.0000000000000968

\section{Abstract \\ Objectives}

To identify putative biomarkers that may serve as quantifiable, biological, nonclinical measures of the pharmacodynamic effect of edaravone in amyotrophic lateral sclerosis (ALS) and to report realworld treatment outcomes.

\section{Methods}

This is a prospective, observational, longitudinal, multicenter (up to 40 sites) US study (Clinicaltrials.gov; NCT04259255) with at least 200 patients with ALS who will receive edaravone for 24 weeks ( 6 cycles; Food and Drug Administration-approved regimen). All participants must either be treatment naive for edaravone or be more than 1 month without receiving any edaravone dose before screening. Biomarker quantification and other assessments will be performed at baseline (before cycle 1) and during cycles 1, 3, and 6. Selected biomarkers of oxidative stress, inflammation, neuronal injury and death, and muscle injury, as well as biomarker discovery panels (EpiSwitch and SOMAscan), will be evaluated and, when feasible, compared with biobanked samples. Clinical efficacy assessments will include the ALS Functional Rating ScaleRevised, King's clinical staging, ALS Assessment Questionnaire-40, Appel ALS Score (Rating Scale), slow vital capacity, hand-held dynamometry and grip strength, and time to specified states of disease progression or death. DNA samples will also be collected for potential genomic evaluation. The predicted rates of progression and survival, and their potential correlations with biomarkers, will be evaluated. Adverse events related to the study will be reported.

\section{Results}

The study is estimated to be completed in 2022 with an interim analysis planned.

\section{Conclusions}

Findings may help to further the understanding of the pharmacodynamic effect of edaravone, including changes in biomarkers, in response to treatment.

Massachusetts General Hospital (JB), Boston; Atrium Health Neurosciences Institute (BB), Carolinas Medical Center, University of North Carolina School of Medicine-Charlotte Campus; Montreal Neurological Institute and Hospital (AG), QC, Canada; Lewis Katz School of Medicine (TH-P), Temple University, Philadelphia, PA; Houston Methodist (S. Appel), TX; University of Miami (MB), FL; Barrow Neurological Institute (RB, JS), Phoenix, AZ; Harvard Medical School (MC), Boston, MA; University of South Florida (CG), Tampa; Oxford BioDynamics Inc. (WW), Wilmington, DE; and Mitsubishi Tanabe Pharma America (WA, CM, SN, S. Apple), Inc., Jersey City, NJ.

Funding information and disclosures are provided at the end of the article. Full disclosure form information provided by the authors is available with the full text of this article at Neurology.org/cp.

The Article Processing Charge was funded by Mitsubishi Tanabe Pharma America, Inc.

This is an open access article distributed under the terms of the Creative Commons Attribution-NonCommercial-NoDerivatives License 4.0 (CC BY-NC-ND), which permits downloading and sharing the work provided it is properly cited. The work cannot be changed in any way or used commercially without permission from the journal. 
Amyotrophic lateral sclerosis (ALS) is a progressive and fatal neurodegenerative disease, characterized by the degeneration of nerve cells of the brain and spinal cord, predominantly upper and lower motor neurons. ${ }^{1}$ There is no cure for ALS. The current US Food and Drug Administration (FDA)-approved treatments for ALS are riluzole (Rilutek; Tiglutek) and edaravone (Radicava) (see FDA.gov). In a clinical trial, edaravone was shown to slow the decline in physical function in ALS. ${ }^{2}$

Biomarkers in ALS are actively evaluated as important tools in designing and implementing clinical trials and monitoring treatment efficacy during trials. ${ }^{3,4}$ Numerous candidates of interest have been identified for various pathophysiologic aspects of ALS, including oxidative stress (e.g., 3-nitrotyrosine [3-NT], 4-hydroxy-2,3-nonenal [4-HNE $],{ }^{5,6}$ F2-isoprostanes, ${ }^{7}$ 8-hydroxydeoxyguanosine $[8-\mathrm{OHdG}],{ }^{7}$ and uric $\operatorname{acid}^{8,9}$ ), inflammation (e.g., matrix metalloproteinases [MMPs] $),{ }^{10}$ neuronal injury and death (e.g., neurofilaments $[\mathrm{Nfs}],{ }^{11,12}$ urinary neurotrophin receptor p75 extracellular domain $\left.\left[\mathrm{p} 75 \mathrm{NTR}^{\mathrm{ECD}}\right]\right),{ }^{13,14}$ and muscle injury (e.g., creatinine). ${ }^{15} 3-\mathrm{NT}$, in particular, has been associated with response to edaravone, with changes observed as early as the first cycle and an almost undetectable level at 6 months, a reduction that correlated with improvements in ALS Functional Rating ScaleRevised (ALSFRS-R) scores. ${ }^{16}$ Nonetheless, many of these biomarkers still require more comprehensive validation. ${ }^{3}$

Given the heightened interest in ALS biomarkers, we sought to study a wide spectrum of putative biomarkers in a broad population of patients with ALS undergoing treatment with edaravone to evaluate their potential use in understanding how the disease progresses and elucidating the mechanism of action and molecular pathways involved in the clinical response to edaravone.

\section{Methods and Biomarker Descriptions}

\section{Study Objectives}

The study aims to identify putative biomarkers that may serve as objective, quantifiable, biological measures of the pharmacodynamic effect of edaravone in ALS and to report clinical outcomes for edaravone in a real-world clinical setting.

\section{Study Design}

This is a prospective, observational, longitudinal study to be conducted at approximately 40 centers in the United States. The study is sponsored by Mitsubishi Tanabe Pharma America. The protocol design and selection of biomarkers and clinical assessments were guided by a steering committee consisting of practicing physicians with extensive background and experience in ALS. The study will be conducted in compliance with the institutional review board at all participating sites and the guidance and regulations from the US FDA, as well as in accordance with the principles of the Declaration of Helsinki and Good Clinical
Practices. Up to 300 adult patients with ALS will be enrolled to ensure that at least 200 patients will complete 6 cycles of treatment. A 4 - to 12-week period is allocated for insurance approval (the patient is responsible for the commercial cost of edaravone) before the first treatment cycle. During this period, screening/ baseline clinical and biomarker assessments will be performed. Participants will be followed from the enrollment date for up to 24 weeks after treatment initiation or until premature study discontinuation. The study design is shown in figure 1 . The investigators and participants may discontinue treatment at any time and for any reason. Participants who discontinue edaravone will continue to be followed, and the investigators will continue to perform clinical and biomarker assessments up to the end of the study or until study discontinuation.

Patients will be prescribed edaravone in accordance with the US prescribing information of the product. The decision to prescribe edaravone to the participants will be made independently of the decision to enroll them in the study. The recommended dose of edaravone is an IV infusion of $60 \mathrm{mg}$ administered over a 60 -minute period. For the first treatment cycle, patients will receive edaravone daily for 14 days, followed by a 14-day drugfree period. In subsequent treatment cycles (cycles 2-6, for a total of 24 weeks), participants will receive daily edaravone for 10 days out of 14 days; each treatment cycle will be followed by a 14-day drug-free period. Edaravone can be administered at the study site, at an infusion center, or at the participant's home. Blood and urine samples will be collected and processed at the clinical study sites.

\section{Participants}

Eligible participants will be male or female patients, aged 18 years or older at enrollment, with a diagnosis of ALS. All participants must either be naive to edaravone or be more than 1 month without receiving any edaravone dose before screening. All enrolled patients must have been prescribed edaravone by the treating physician in accordance with good clinical judgment and within the approved indication before study enrollment. These patients must be able to obtain commercial edaravone and be likely to complete 6 cycles of treatment per investigator estimation. Taking current edaravone patients off of their active treatment or delaying the start of treatment so they can become eligible for the study is highly discouraged. Participants will be excluded from the study if they have any contraindication to edaravone or are participating in another interventional clinical trial.

\section{Standard Protocol Approvals, Registrations, and Patient Consents}

The study is registered with Clinicalstrials.gov (identification number: NCT04259255). The study will be conducted in compliance with current Good Clinical Practice defined by the International Conference on Harmonisation and the ethical principles of the Declaration of Helsinki. The study protocol was approved by all relevant institutional review boards. All participants must provide written informed consent before any studyrelated activities are performed. 


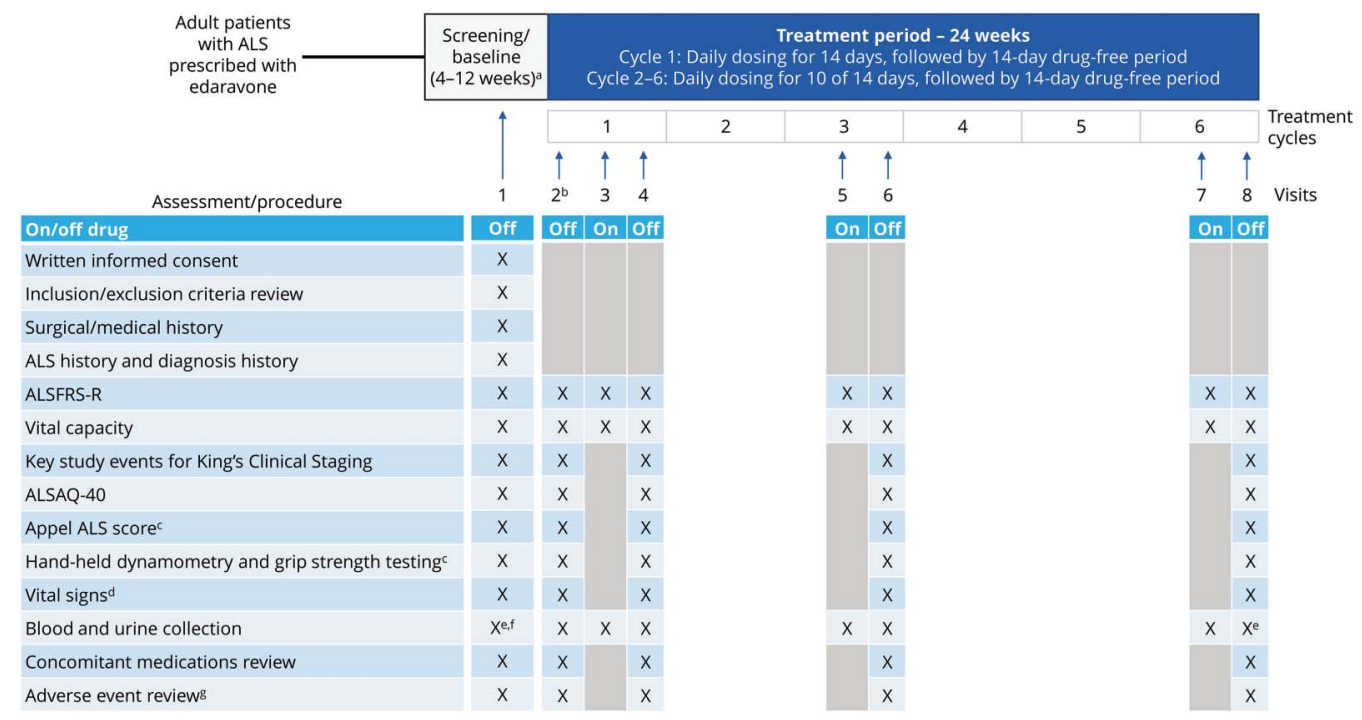

${ }^{a}$ Time between screening/baseline to day 1 of cycle 1 may take approximately 4-12 weeks for insurance approval. ${ }^{b}$ Visit 2 should occur $0-2$ days before starting edaravone treatment. For visits while the patient is on drug, target the visit to occur 1-5 days before stopping their infusions for that cycle. For visits while the patient is off drug, target the visit to occur 0-4 days before beginning their next edaravone cycle. ${ }^{\circ}$ The Appel ALS Score and hand-held dynamometry

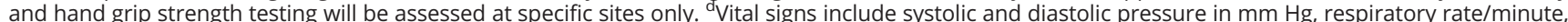
heart rate/minute, temperature, and weight. Height will be assessed at screening/baseline only. ${ }^{e} \mathrm{Clinical}$ labs to be completed at these visits. ${ }^{\mathrm{f}}$ Whole blood collection for DNA whole-genome sequencing can be collected following consent at the screening/baseline visit or any subsequent study visit. ${ }^{\circ}$ Only adverse events that occur after signing of the consent form and that are directly related to study procedures will be recorded. ALS $=$ amyotrophic lateral sclerosis; ALSAQ-40 = ALS Assessment Questionnaire-40; ALSFRS-R = ALS Functional Rating Scale-Revised.

\section{Assessments}

An assessment schedule is shown in figure 1. At 0-2 days before starting edaravone treatment, assessments for biomarkers, clinical outcomes, and safety events will be conducted. Assessments of biomarkers, ALSFRS-R, and vital capacity will be conducted at all visits during both on- and off-treatment periods, whereas all other clinical outcomes and safety assessments will be conducted during the off-treatment period on visits 2 and 4 of cycle 1, visit 6 of cycle 3, and visit 8 of cycle 6 .

\section{Biomarker Assessments}

Biomarker quantification will be performed at baseline and during cycles 1,3 , and 6 . Assessments during on and off periods in the drug cycle will be used for peak/trough analyses. Urine and blood (for plasma and serum) samples will be collected at prespecified time points throughout the study (figure 1). Selected biomarkers of oxidative stress, inflammation, and neuronal injury and death, as well as biomarker discovery panels (e.g., EpiSwitch and SOMAscan), will be evaluated (table 1; also see next section). As an option, blood samples may be collected at the screening/baseline (before administration of treatment) or any subsequent study visit and stored for genome sequencing and other research purposes.

\section{Clinical Assessments}

Clinical outcome assessments will be performed at baseline and at prespecified time points throughout the study; they include ALSFRS-R, King's clinical staging, ALS Assessment Questionnaire-40, Appel ALS Score (selected sites), measurement of slow vital capacity, hand-held dynamometry (selected sites), and bilateral grip strength (selected sites) (table 2 ). Additional assessments of disease progression will include the time to milestones of disease progression, including wheelchair use, speech loss, initiation of noninvasive ventilation, tube feeding, and death. Most outcome assessments are evaluated at off-drug visits. ALSFRS-R score and slow vital capacity will be evaluated more frequently, at both on-drug and off-drug visits, for a more comprehensive assessment of correlation with biomarkers during the entire treatment period. In parallel, via Origent modeling, clinical data collected in the study will be used to (1) predict realworld treatment outcomes for up to 36 weeks, (2) predict patients' rates of progression and survival (using the Pooled Resource Open-Access ALS Clinical Trials database), and (3) correlate changes in biomarkers with predicted rates of disease progression.

\section{Safety Assessments}

Safety parameters, including adverse events (AEs), will be assessed prospectively throughout the study. Serious and nonserious AEs that are considered related to study procedures, including treatment with edaravone, by the site investigator will be reported. Safety assessments will be conducted at baseline/screening and during off-drug visits.

\section{Data Management and Statistical Methods}

All data analysis will be conducted at the Massachusetts General Hospital Biostatistics Center. Data and biomarker workflow is shown in figure 2. 
Table 1 Biomarkers Being Assessed

\begin{tabular}{|c|c|c|}
\hline Biomarker & Matrix & Assay \\
\hline \multicolumn{3}{|l|}{ Oxidative stress } \\
\hline 4-Hydroxy-2,3-nonenal & Plasma & ELISA \\
\hline F2-isoprostanes & Plasma & ELISA \\
\hline $\begin{array}{l}\text { 8-Hydroxy-2'- } \\
\text { deoxyguanosine }\end{array}$ & Plasma & ELISA \\
\hline 3-Nitrotyrosine & Serum & $\begin{array}{l}\text { Electrochemiluminescence } \\
\text { and mass spectrometry }\end{array}$ \\
\hline Urate & Serum & Uricase method \\
\hline \multicolumn{3}{|l|}{ Inflammation } \\
\hline $\begin{array}{l}\text { Matrix } \\
\text { metalloproteinase-9 }\end{array}$ & Serum & $\begin{array}{l}\text { Multianalyte profiling } \\
\text { immunoassay }\end{array}$ \\
\hline \multicolumn{3}{|l|}{ Neuronal injury and death } \\
\hline $\begin{array}{l}\text { Neurofilament heavy } \\
\text { and light chain proteins }\end{array}$ & Serum & ELISA \\
\hline $\begin{array}{l}\text { Urinary p75 neurotrophin } \\
\text { receptor extracellular } \\
\text { domain }\end{array}$ & Urine & ELISA \\
\hline \multicolumn{3}{|l|}{ Muscle injury } \\
\hline Creatinine & $\begin{array}{l}\text { Serum } \\
\text { and urine }\end{array}$ & $\begin{array}{l}\text { Enzymatic creatinine } \\
\text { method }\end{array}$ \\
\hline \multicolumn{3}{|l|}{ Biomarker discovery panels } \\
\hline $\begin{array}{l}\text { Epigenetic biomarkers } \\
\text { (EpiSwitch) }\end{array}$ & $\begin{array}{l}\text { Whole } \\
\text { blood }\end{array}$ & Oxford BioDynamics, Plc \\
\hline $\begin{array}{l}\text { Protein biomarkers } \\
\text { (SOMAscan) }\end{array}$ & Plasma & SomaLogic, Inc. \\
\hline
\end{tabular}

Sample size is calculated to achieve enough statistical power as pertains to the selected assessments. A single treatment group of 225 participants will provide $80 \%$ power for a statistically significant difference of at least 0.21 in ALSFRS-R scores between baseline and post-24-week treatment, assuming a common $\mathrm{SD}$ of 0.70 , a correlation between pairs of 0.25 , 2-sided testing, and an alpha level of 0.05 . In comparison, 0.21 is greater than 10 times less than that observed in the original phase 2 and 3 studies that showed that edaravone is beneficial in delaying the ALS progression. ${ }^{17}$ In addition, a sample size of 225 participants with the same correlation assumption has $80 \%$ power in a 2 -sided test at the 0.05 level to detect a mean paired difference in 8 -OHdG biomarker $(\mathrm{ng} / \mathrm{mL})$ of 0.15 , assuming a pooled SD of $0.5 .^{18}$

The analysis set will include all enrolled patients who received at least 1 dose of edaravone. Postbaseline values and absolute change from baseline in the continuous outcome variables will be summarized with descriptive statistics and tested vs 0 using a paired $t$ test. Longitudinal changes during the 24-week study will be estimated by a linear mixed-effects model adjusting for withinparticipant variability and residual variation. Time to specified King's clinical stages (all except stage 5), permanent assisted ventilation, and tracheostomy-free survival, as well as overall survival, will be assessed with Kaplan-Meier analyses. A Cox regression model will be used to analyze the relationship between independent variables at baseline and time to event. Origent modeling (e.g., regression) will be applied to both clinical and biomarker data to evaluate longer-term treatment outcomes and determine rates of disease progression and survival and any correlation with biomarkers. An interim analysis has been planned to gauge the feasibility of the study and the quality of the data.

\section{Data Availability}

Data are available on request to Mitsubishi Tanabe Pharma America, Inc, from researchers at academic institutions.

\section{Discussion}

REFINE-ALS is a prospective, observational, longitudinal clinical study conducted in a broad, real-world population of patients with ALS treated with edaravone and is aimed at improving our understanding and application of biomarkers as they pertain to the use of edaravone in ALS. The potential use of biomarkers in patient care and in research and clinical trials are the applications of interest. This is an important and growing area of research as biomarkers are increasingly recognized and being actively evaluated as potential assessment and evaluation tools in clinical studies not only in ALS but also in a variety of other diseases. In the latter, some biomarkers have already been qualified to be used in clinical practice and drug development by the US FDA (see FDA.gov). The results of this study aim to address this unmet need with more practical data on a broad range of biomarkers from edaravone-treated patients in a realworld setting. An interim analysis has been planned to ascertain the feasibility of the study, including providing insights into whether meaningful data can be generated early during the course of the study, whether the study design was sound and the sample size was appropriate, and whether biomarkers change from baseline with edaravone treatment.

There are several strengths to the study. First, a broad range of biomarkers was chosen to ensure a more complete understanding of their roles in patients undergoing treatment with edaravone. They were grouped based on their reported involvements in oxidative stress, inflammation, neuronal injury and death, and muscle injury. In addition, exploratory biomarker panels based on epigenetic and proteomic technologies were included.

\section{Oxidative Stress}

An increase in oxidative stress has been proposed to play a role in ALS. The oxidative stress biomarkers to be analyzed in the study include 4-HNE, F2-isoprostanes, 8-OHdG (also known as 8-Oxo-7,8-dihydro-2' -deoxyguanosine or 8-Oxo-dG), and 3NT. ${ }^{5,19} 4$-HNE is one of the main, and most toxic, peroxidation products of omega- 6 fatty acid lipids. ${ }^{5}$ Significantly elevated levels of 4-HNE, measured by high-performance liquid chromatography, have been found in the serum and CSF of patients 
Table 2 Clinical Assessments

\begin{tabular}{|c|c|}
\hline Assessments & Measures \\
\hline ALSFRS-R & $\begin{array}{l}\text { Assessment of patient's capability and } \\
\text { independence in } 12 \text { functional activities } \\
\text { (i.e., speech, salivation, swallowing, } \\
\text { handwriting, cutting food and handling } \\
\text { utensils, dressing and hygiene, turning in } \\
\text { bed and adjusting bed clothes, walking, } \\
\text { climbing stairs, dyspnea, orthopnea, and } \\
\text { respiratory insufficiency) }\end{array}$ \\
\hline King's clinical staging & $\begin{array}{l}\text { Evaluation of number of body regions } \\
\text { affected by ALS and presence of } \\
\text { respiratory or nutritional failure } \\
\text { ( } 5 \text { stages) }\end{array}$ \\
\hline ALSAQ-40 & $\begin{array}{l}\text { A patient-reported outcome assessment } \\
\text { for physical mobility, activities of daily } \\
\text { living and independence, eating and } \\
\text { drinking, communication, and emotional } \\
\text { reactions }\end{array}$ \\
\hline Appel ALS Score & $\begin{array}{l}\text { Measure of dysfunction for bulbar, } \\
\text { respiratory, muscle strength, and lower } \\
\text { and upper extremity function }\end{array}$ \\
\hline Slow vital capacity & Measure of respiratory muscle strength \\
\hline Hand-held dynamometry & $\begin{array}{l}\text { Quantitative measure of muscle } \\
\text { strength in } 6 \text { muscle groups (i.e., } \\
\text { shoulder flexion, elbow flexion, elbow } \\
\text { extension, hip flexion, knee flexion, and } \\
\text { knee extension) and for wrist extension, } \\
\text { first dorsal interosseous contraction, } \\
\text { and ankle dorsiflexion }\end{array}$ \\
\hline Bilateral grip strength & $\begin{array}{l}\text { Quantitative measure of isometric } \\
\text { strength of the hand and forearm } \\
\text { muscles }\end{array}$ \\
\hline $\begin{array}{l}\text { Milestones of disease } \\
\text { progression }\end{array}$ & $\begin{array}{l}\text { Record date of onset for wheelchair use, } \\
\text { speech loss, initiation of noninvasive } \\
\text { ventilation, and tube feeding }\end{array}$ \\
\hline
\end{tabular}

Abbreviatons: ALS = amyotrophic lateral sclerosis; ALSAQ-40 = ALS Assessment Questionnaire-40; ALSFRS-R = ALS Functional Rating Scale-Revised.

with sporadic ALS compared with healthy individuals and those with other neurologic diseases, and the levels may also correlate with the severity of disease. ${ }^{5}$ Increased 4-HNE has been associated with aberrant modification of proteins, some of which include the membrane transport systems that protect neurons from excitotoxic and metabolic injury that can culminate in motor neuron degeneration. ${ }^{20}$ F2-isoprostanes, prostaglandin-like compounds formed in vivo primarily by free radical-catalyzed peroxidation of arachidonic acid, have been found to be elevated in the urine of patients with ALS. ${ }^{7,19} 8$ OHdG is an oxidized nucleoside of DNA and may be a marker of generalized oxidative stress and an indicator for DNA damage and repair. ${ }^{21}$ Patients with sporadic ALS have been found to have significantly higher levels of $8-\mathrm{OHdG}$ than healthy individuals. ${ }^{7}$ Serum urate, in contrast, may have a protective influence on neuronal cell death because of its antioxidant properties. ${ }^{9}$ In patients with ALS, serum urate levels are reduced compared with those in healthy individuals, and lower urate levels may be associated with greater rates of decline in ALSFRS$\mathrm{R}$ and forced vital capacity. ${ }^{15}$ Furthermore, higher baseline uric acid levels correlate with a lower risk of mortality; specifically, up to a $39 \%$ reduction in risk of death was found in men with ALS for every $1 \mathrm{mg} / \mathrm{dL}$ increase in uric acid levels. ${ }^{8,9} 3-\mathrm{NT}$, a marker of oxidative damage, is mediated by peroxynitrite. ${ }^{6}$ The $3-\mathrm{NT}$ levels have been found to be elevated in the motor neurons of the spinal cord and the CSF of some patients with ALS, ${ }^{6,22}$ whereas in others, no differences were observed. ${ }^{23,24}$ Notably, the amount of 3-NT in the CSF decreased to almost undetectable levels after 6 months of treatment with edaravone. ${ }^{16}$

\section{Inflammation}

MMPs form a protein family of zinc-containing endopeptidases that play a role in neuroinflammation and may be involved in neurodegeneration. The MMP-9 subtype is expressed in motor neurons in the spinal cord. In patients with ALS, the expression of MMP-9 has been shown to be elevated in the serum and CSF, and in a prospective study, its increased level in the CSF has been associated with rapidly progressing ALS (evaluated by monthly changes on the Medical Research Council sum score). ${ }^{10,25}$ Of interest, in a SOD1 mouse model of ALS, inhibition of MMP-9 appeared to reduce the degeneration of motor neurons and delay muscle denervation, as well as prolong survival. ${ }^{26}$

\section{Neuronal Injury and Death}

$\mathrm{Nfs}$ and $\mathrm{p}^{75 N T R^{\mathrm{ECD}}}$ are 2 potential biomarkers for neuronal injury and death. Nfs are neuronal intermediate filament proteins that are composed of light, medium, and heavy chain subunits, and mutations in the heavy chain gene have been associated with increased susceptibility to ALS. ${ }^{11,12}$ Patients with ALS have higher levels of both heavy and light Nf chain proteins in the blood and CSF than healthy people, which may be associated with more rapid disease progression and reduced survival. ${ }^{12,27}$ The light Nf chain and the phosphorylated form of Nf heavy chain were found to be elevated in presymptomatic individuals at genetic risk for $\mathrm{ALS}^{28}$ and potentially in those

Figure 2 Data and Biomarker Workflow

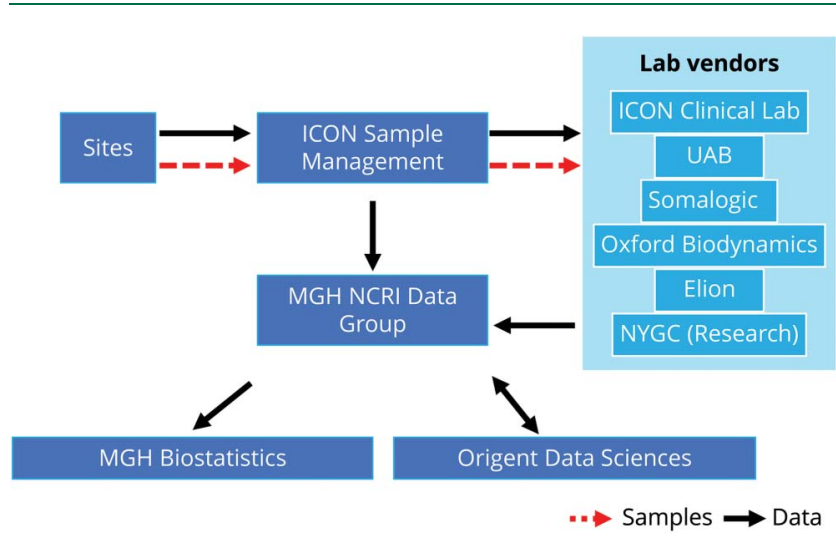

MGH NCRI = Massachusetts General Hospital Neurological Clinical Research Institute; NYGC = New York Genome Center; UAB = University of Alabama at Birmingham. 
with upper motor neuron-dominant disease as opposed to those with typical ALS. ${ }^{12,28,29}$ Notably, both Nf heavy and light chains have shown high sensitivity and specificity in classifying ALS vs various control groups. ${ }^{30,31}$

p75NTR expression is increased in motor neurons upon cellular injury, and this increase has been shown to lead to neuronal injury and death. Mice that lacked the receptors had significantly more surviving motor neurons following axotomy than did those whose receptors were intact. ${ }^{13}$ In patients with ALS, urinary p75NTR ${ }^{\mathrm{ECD}}$ level is significantly higher than in people without the disease. ${ }^{14}$ Moreover, higher p75NTR levels were associated with more rapidly progressive disease, based on prospective clinical follow-up. ${ }^{14}$ In addition, urinary p $75 \mathrm{NTR}^{\mathrm{ECD}}$ level increases over time as the disease worsens, supporting its role as a candidate biomarker of disease progression. ${ }^{14}$

\section{Muscle Injury}

Creatinine has historically been postulated as a biomarker for muscle mass, given that people with higher muscle mass have higher levels of creatinine. ${ }^{32}$ Patients with ALS, compared with healthy controls, have lower levels of creatinine. ${ }^{15}$ Lower creatinine levels in patients with ALS may also correlate with worsening of the disease, as assessed by the ALSFRS-R score and forced vital capacity. ${ }^{15}$

\section{Biomarker Discovery Panels}

EpiSwitch and SOMAscan are 2 high-throughput platforms designed to identify and evaluate epigenetic and proteomic biomarkers, respectively. EpiSwitch is a technology platform for identifying epigenetic biomarkers by analyzing changes in genomic architecture. It has been used as a biomarker modality in a range of diseases and, in ALS, has been reported to show potential utility as a diagnostic aid and a prognostic tool to assess disease progression rates after a diagnosis is made. ${ }^{33-39}$ SOMAscan is an aptamer-based proteomics assay for protein biomarkers that is capable of high-throughput measurement of human protein analytes in serum, plasma, and other biologic matrices with high sensitivity and specificity. ${ }^{40}$ SOMAscan has been reported to show potential utility in diagnosing, assessing risks, predicting and assessing therapeutic response, and providing mechanistic insights into disease pathophysiology in various diseases, including Duchenne muscular dystrophy, ${ }^{41}$ Alzheimer disease, ${ }^{42}$ and inflammatory bowel disease. ${ }^{43}$

Another strength of the study is the inclusion of a fuller spectrum of the disease via broad inclusion criteria and a real-world patient population. Accordingly, more robust and clinically relevant insights and results are envisioned for both the evaluations of biomarkers and the reporting of real-world treatment outcomes for edaravone. Biomarkers were selected to represent several biological components in ALS and mechanism(s) of action of edaravone. In addition, high-throughput platforms for discovery and testing of novel biomarkers that span both the genomic and proteomic landscape may extend the capacity of the study to better identify and evaluate putative candidates. The selected biomarkers in the study have been chosen based on their association with the disease, including potential correlation with treatment outcomes, as demonstrated in previous studies.

Limitations of the study included the absence of a parallel control group that may allow for a comparison of clinical responses with the treated group and the lack of pretreatment longitudinal biomarker data that may provide a more comprehensive understanding of the longitudinal changes in the selected biomarkers.

Assessments of treatment outcomes, including ALSFRS-R and King's clinical staging, will be reported. Robust, real-world data on the clinical outcomes of edaravone may improve the evidence-based management of patients with ALS by filling the gap between the evidence generated by randomized clinical trials and their effect in the real world, particularly for a heterogeneous disease such as ALS. Clinical data collected at baseline and treatment response at both on- and off-drug periods will allow for detailed pharmacodynamic evaluation of edaravone in a real-world setting. Potential correlation between changes in biomarkers and treatment outcomes may help guide their use in clinical practice and research. In particular, identifying a biomarker that can predict change in patients' clinical status (e.g., ALSFRS-R) or the anatomic spread of ALS based on the number of affected regions (e.g., King's ALS clinical staging) may be useful in clinical practice and drug development.

The findings of this study may help to further the understanding of the pharmacodynamic effect of edaravone during the treatment period, which involves 2 weeks on drug and 2 weeks off drug. Biomarkers that may show a strong correlation with disease progression and treatment outcomes may form a panel of biomarkers to be potentially added to a patient registry study, where they will be analyzed for their feasibility and validity to become incorporated into the clinical treatment plan for edaravone. These biomarkers will comprise an important assessment tool not only for patients' daily treatment regimens but also for future clinical programs. Additional insights may be gained into the mechanisms of action of treatments such as edaravone by differentiating the treatment effect across different pathophysiologic axes. Finally, the findings of this study will provide additional real-world experience with edaravone as it relates to both safety and clinical outcomes.

\section{Acknowledgment}

The authors thank Dr. Rakesh Patel, University of Alabama, Birmingham, for providing invaluable comments and suggestions throughout the study planning phase, particularly pertaining to the use of oxidative stress biomarkers in ALS. They also thank $p$-value communications for providing support for technical writing, editing, and publication assistance. 
TAKE-HOME POINTS

$\rightarrow$ REFINE-ALS is a prospective, observational, longitudinal clinical study conducted in a broad population of patients with ALS treated with edaravone in a real-world setting.

$\rightarrow$ The study aims to improve our understanding and application of biomarkers as they pertain to the use of edaravone in ALS, particularly their potential use in patient care and in research and clinical trials.

$\rightarrow$ The study will also evaluate both safety and clinical outcomes of edaravone in a real-world setting.

\section{Study Funding}

The study was funded by Mitsubishi Tanabe Pharma America, Inc. (MTPA).

\section{Disclosure}

J. Berry and B. Brooks are consultants for MTPA. A. Genge is on the advisory board for Alexion, AL-S Pharma, AveXis, Biogen, Brainstorm, Clene Nanomedicine, MTPA, Novartis, Roche, and Sanofi. T. Heiman-Patterson reports personal fees from MTPA and Cytokinetics as a consultant on the publications committee; she is a consultant for ITF Pharma; she also reports funding for clinical trials from Amylyx, Cytokinetics, MTPA, Orion, and UCB. S. Appel reports no disclosures. M. Benatar reports grants from the NIH, the ALS Association, the Muscular Dystrophy Association, the Centers for Disease Control and Prevention, the Department of Defense, and Target ALS during the conduct of the study and personal fees from Mitsubishi Tanabe Pharma, AveXis, and Genentech, outside of the submitted work; in addition, he has a provisional patent entitled "Determining Onset of Amyotrophic Lateral Sclerosis"; he also serves as a site investigator on clinical trials funded by Biogen and Orphazyme. R. Bowser is founder and president of Iron Horse Diagnostics, a company focused on commercialization of diagnostic and prognostic indicators of neurologic diseases; he also reports grants from the NIH, the ALS Association, the Muscular Dystrophy Association, and Target ALS during the conduct of this study; he received personal fees from Mitsubishi Tanabe Pharma as a consultant and is on the scientific advisory board of Aural Analytics. M. Cudkowicz reports no disclosures. C. Gooch is a consultant in ALS therapeutics and research for MTPA, a member of the Board of Trustees for the ALS Association, and a member of the editorial board for the Journal of Neurology. J. Shefner reports funding from the NIH, the ALS Association, the ALS Finding a Cure Foundation, Amylyx, Apic Bioscience, Cytokinetics, and Mitsubishi Pharma America and reports personal fees from Cytokinetics, MTPA, Neurosense, and Orphazyme. J. Westra is an employee of Oxford
BioDynamics, Inc. W. Agnese and C. Merrill are former employees of MTPA. S. Nelson and S. Apple are employees of MTPA. Full disclosure form information provided by the authors is available with the full text of this article at Neurology.org/cp.

\section{Publication History}

Received by Neurology: Clinical Practice February 14, 2020. Accepted in final form September 3, 2020.

\section{Appendix Authors}

\begin{tabular}{|c|c|c|}
\hline Name & Location & Contribution \\
\hline James Berry, MD & $\begin{array}{l}\text { Massachusetts General } \\
\text { Hospital, Boston }\end{array}$ & $\begin{array}{l}\text { Designed and } \\
\text { conceptualized the study } \\
\text { and drafted and critically } \\
\text { revised the manuscript }\end{array}$ \\
\hline $\begin{array}{l}\text { Benjamin } \\
\text { Brooks, MD }\end{array}$ & $\begin{array}{l}\text { Atrium Health Neurosciences } \\
\text { Institute, Carolinas Medical } \\
\text { Center, University of North } \\
\text { Carolina School of } \\
\text { Medicine-Charlotte Campus }\end{array}$ & $\begin{array}{l}\text { Designed and } \\
\text { conceptualized the study } \\
\text { and drafted and critically } \\
\text { revised the manuscript }\end{array}$ \\
\hline $\begin{array}{l}\text { Angela Genge, } \\
\text { MD }\end{array}$ & $\begin{array}{l}\text { Montreal Neurological } \\
\text { Institute and Hospital, QC, } \\
\text { Canada }\end{array}$ & $\begin{array}{l}\text { Designed and } \\
\text { conceptualized the study } \\
\text { and drafted and critically } \\
\text { revised the manuscript }\end{array}$ \\
\hline $\begin{array}{l}\text { Terry Heiman- } \\
\text { Patterson, MD }\end{array}$ & $\begin{array}{l}\text { Lewis Katz School of } \\
\text { Medicine, Temple } \\
\text { University, Philadelphia, } \\
\text { PA }\end{array}$ & $\begin{array}{l}\text { Designed and } \\
\text { conceptualized the study } \\
\text { and drafted and critically } \\
\text { revised the manuscript }\end{array}$ \\
\hline $\begin{array}{l}\text { Stanley Appel, } \\
\text { MD }\end{array}$ & Houston Methodist, TX & $\begin{array}{l}\text { Designed and } \\
\text { conceptualized the study } \\
\text { and drafted and critically } \\
\text { revised the manuscript }\end{array}$ \\
\hline $\begin{array}{l}\text { Michael Benatar, } \\
\text { MD, PhD }\end{array}$ & University of Miami, FL & $\begin{array}{l}\text { Designed and } \\
\text { conceptualized the study } \\
\text { and drafted and critically } \\
\text { revised the manuscript }\end{array}$ \\
\hline $\begin{array}{l}\text { Robert Bowser, } \\
\text { PhD }\end{array}$ & $\begin{array}{l}\text { Barrow Neurological } \\
\text { Institute, Phoenix, AZ }\end{array}$ & $\begin{array}{l}\text { Designed and } \\
\text { conceptualized the study } \\
\text { and drafted and critically } \\
\text { revised the manuscript }\end{array}$ \\
\hline $\begin{array}{l}\text { Merit } \\
\text { Cudkowicz, MD }\end{array}$ & $\begin{array}{l}\text { Harvard Medical School, } \\
\text { Boston, MA }\end{array}$ & $\begin{array}{l}\text { Designed and } \\
\text { conceptualized the study } \\
\text { and drafted and critically } \\
\text { revised the manuscript }\end{array}$ \\
\hline $\begin{array}{l}\text { Clifton Gooch, } \\
\text { MD }\end{array}$ & $\begin{array}{l}\text { University of South } \\
\text { Florida, Tampa }\end{array}$ & $\begin{array}{l}\text { Designed and } \\
\text { conceptualized the study } \\
\text { and drafted and critically } \\
\text { revised the manuscript }\end{array}$ \\
\hline $\begin{array}{l}\text { Jeremy Shefner, } \\
\text { MD, PhD }\end{array}$ & $\begin{array}{l}\text { Barrow Neurological } \\
\text { Institute, Phoenix, AZ }\end{array}$ & $\begin{array}{l}\text { Designed and } \\
\text { conceptualized the study } \\
\text { and drafted and critically } \\
\text { revised the manuscript }\end{array}$ \\
\hline $\begin{array}{l}\text { Jurjen Westra, } \\
\text { PhD }\end{array}$ & $\begin{array}{l}\text { Oxford BioDynamics Inc., } \\
\text { Wilmington, DE }\end{array}$ & $\begin{array}{l}\text { Designed and } \\
\text { conceptualized the study } \\
\text { and drafted and critically } \\
\text { revised the manuscript }\end{array}$ \\
\hline $\begin{array}{l}\text { Wendy Agnese, } \\
\text { PharmD }\end{array}$ & $\begin{array}{l}\text { Mitsubishi Tanabe } \\
\text { Pharma America, Inc., } \\
\text { Jersey City, NJ }\end{array}$ & $\begin{array}{l}\text { Designed and } \\
\text { conceptualized the study } \\
\text { and drafted and critically } \\
\text { revised the manuscript }\end{array}$ \\
\hline
\end{tabular}

Continued 
Appendix (continued)

\begin{tabular}{lll}
\hline Name & Location & Contribution \\
\hline $\begin{array}{l}\text { Charlotte } \\
\text { Merrill, PhD, }\end{array}$ & $\begin{array}{l}\text { Mitsubishi Tanabe } \\
\text { Pharma America, Inc., } \\
\text { Jersey City, NJ }\end{array}$ & $\begin{array}{l}\text { Designed and } \\
\text { conceptualized the study } \\
\text { and drafted and critically } \\
\text { revised the manuscript }\end{array}$ \\
\hline $\begin{array}{l}\text { Sally Nelson, MS, } \\
\text { PhD }\end{array}$ & $\begin{array}{l}\text { Mitsubishi Tanabe } \\
\text { Pharma America, Inc., } \\
\text { Jersey City, NJ }\end{array}$ & $\begin{array}{l}\text { Designed and } \\
\text { conceptualized the study } \\
\text { and drafted and critically } \\
\text { revised the manuscript }\end{array}$ \\
\hline $\begin{array}{l}\text { Stephen Apple, } \\
\text { MD }\end{array}$ & $\begin{array}{l}\text { Mitsubishi Tanabe } \\
\text { Pharma America, Inc., } \\
\text { Jersey City, NJ }\end{array}$ & $\begin{array}{l}\text { Designed and } \\
\text { conceptualized the study } \\
\text { and drafted and critically } \\
\text { revised the manuscript }\end{array}$
\end{tabular}

\section{References}

1. Brown RH, Al-Chalabi A. Amyotrophic lateral sclerosis. N Engl J Med 2017;377: $162-172$.

2. Writing Group on Behalf of the Edaravone ALS 19 Study Group. Safety and efficacy of edaravone in well defined patients with amyotrophic lateral sclerosis: a randomised, double-blind, placebo-controlled trial. Lancet Neurol 2017;16:505-512.

3. Benatar M, Boylan K, Jeromin A, et al. ALS biomarkers for therapy development: state of the field and future directions. Muscle Nerve 2016;53:169-182.

4. van den Berg LH, Sorenson E, Gronseth G, et al. Revised Airlie House consensus guidelines for design and implementation of ALS clinical trials. Neurology 2019;92: e1610-e1623.

5. Simpson EP, Henry YK, Henkel JS, Smith RG, Appel SH. Increased lipid peroxidation in sera of ALS patients: a potential biomarker of disease burden. Neurology 2004;62:1758-1765.

6. Beal MF, Ferrante RJ, Browne SE, Matthews RT, Kowall NW, Brown RH Jr. Increased 3-nitrotyrosine in both sporadic and familial amyotrophic lateral sclerosis. Ann Neurol 1997;42:644-654.

7. Mitsumoto H, Santella RM, Liu X, et al. Oxidative stress biomarkers in sporadic ALS. Amyotroph Lateral Scler 2008;9:177-183.

8. Paganoni S, Nicholson K, Chan J, et al. Urate levels predict survival in amyotrophic lateral sclerosis: analysis of the expanded Pooled Resource Open-Access ALS clinical trials database. Muscle Nerve 2018;57:430-434.

9. Paganoni S, Zhang M, Quiroz Zarate A, et al. Uric acid levels predict survival in men with amyotrophic lateral sclerosis. J Neurol 2012;259:1923-1928.

10. Demestre M, Parkin-Smith G, Petzold A, Pullen AH. The pro and the active form of matrix metalloproteinase- 9 is increased in serum of patients with amyotrophic lateral sclerosis. J Neuroimmunol 2005;159:146-154.

11. Figlewicz DA, Krizus A, Martinoli MG, et al. Variants of the heavy neurofilament subunit are associated with the development of amyotrophic lateral sclerosis. Hum Mol Genet 1994;3:1757-1761.

12. $\mathrm{Xu} \mathrm{Z}$, Henderson RD, David M, McCombe PA. Neurofilaments as biomarkers for amyotrophic lateral sclerosis: a systematic review and meta-analysis. PLoS One 2016; $11: \mathrm{e} 0164625$.

13. Ferri CC, Moore FA, Bisby MA. Effects of facial nerve injury on mouse motoneurons lacking the p75 low-affinity neurotrophin receptor. J Neurobiol 1998;34:1-9.

14. Shepheard SR, Wuu J, Cardoso M, et al. Urinary p75(ECD): a prognostic, disease progression, and pharmacodynamic biomarker in ALS. Neurology 2017;88: 1137-1143.

15. Ikeda K, Hirayama T, Takazawa T, Kawabe K, Iwasaki Y. Relationships between disease progression and serum levels of lipid, urate, creatinine and ferritin in Japanese patients with amyotrophic lateral sclerosis: a cross-sectional study. Intern Med 2012; 51:1501-1508.

16. Yoshino H, Kimura A. Investigation of the therapeutic effects of edaravone, a free radical scavenger, on amyotrophic lateral sclerosis (Phase II study). Amyotroph Lateral Scler 2006;7:241-245.

17. Abe K, Itoyama Y, Sobue G, et al. Confirmatory double-blind, parallel-group, placebocontrolled study of efficacy and safety of edaravone (MCI-186) in amyotrophic lateral sclerosis patients. Amyotroph Lateral Scler Frontotemporal Degener 2014;15:610-617.
18. Blasco H, Corcia P, Moreau C, et al. 1H-NMR-based metabolomic profiling of CSF in early amyotrophic lateral sclerosis. PLoS One 2010;5:e13223.

19. D’Amico E, Factor-Litvak P, Santella RM, Mitsumoto H. Clinical perspective on oxidative stress in sporadic amyotrophic lateral sclerosis. Free Radic Biol Med 2013; 65:509-527.

20. Pedersen WA, Fu W, Keller JN, et al. Protein modification by the lipid peroxidation product 4-hydroxynonenal in the spinal cords of amyotrophic lateral sclerosis patients. Ann Neurol 1998;44:819-824.

21. Wu LL, Chiou CC, Chang PY, Wu JT. Urinary 8-OHdG: a marker of oxidative stress to DNA and a risk factor for cancer, atherosclerosis and diabetics. Clin Chim Acta 2004;339:1-9.

22. Tohgi H, Abe T, Yamazaki K, Murata T, Ishizaki E, Isobe C. Remarkable increase in cerebrospinal fluid 3-nitrotyrosine in patients with sporadic amyotrophic lateral sclerosis. Ann Neurol 1999;46:129-131.

23. Ryberg H, Soderling AS, Davidsson P, Blennow K, Caidahl K, Persson LI. Cerebrospinal fluid levels of free 3-nitrotyrosine are not elevated in the majority of patients with amyotrophic lateral sclerosis or Alzheimer's disease. Neurochem Int 2004;45: $57-62$.

24. Mendonca DM, Martins SC, Higashi R, et al. Neurofilament heavy subunit in cerebrospinal fluid: a biomarker of amyotrophic lateral sclerosis? Amyotroph Lateral Scler 2011;12:144-147.

25. Fang L, Huber-Abel F, Teuchert M, et al. Linking neuron and skin: matrix metalloproteinases in amyotrophic lateral sclerosis (ALS). J Neurol Sci 2009;285:62-66.

26. Kaplan A, Spiller KJ, Towne C, et al. Neuronal matrix metalloproteinase-9 is a determinant of selective neurodegeneration. Neuron 2014;81:333-348.

27. Benatar M, Zhang L, Wang L, et al. Validation of serum neurofilaments as prognostic and potential pharmacodynamic biomarkers for ALS. Neurology 2020;95:e59-e69.

28. Benatar M, Wuu J, Lombardi V, et al. Neurofilaments in pre-symptomatic ALS and the impact of genotype. Amyotroph Lateral Scler Frontotemporal Degener 2019;20: 538-548.

29. Brettschneider J, Petzold A, Sussmuth SD, Ludolph AC, Tumani H. Axonal damage markers in cerebrospinal fluid are increased in ALS. Neurology 2006;66:852-856.

30. Verde F, Steinacker P, Weishaupt JH, et al. Neurofilament light chain in serum for the diagnosis of amyotrophic lateral sclerosis. J Neurol Neurosurg Psychiatry 2019;90: 157-164.

31. Chen X, Chen $Y$, Wei $Q$ et al. Assessment of a multiple biomarker panel for diagnosis of amyotrophic lateral sclerosis. BMC Neurol 2016;16:173.

32. Baxmann AC, Ahmed MS, Marques NC, et al. Influence of muscle mass and physical activity on serum and urinary creatinine and serum cystatin C. Clin J Am Soc Nephrol 2008;3:348-354.

33. Salter M, Corfield E, Ramadass A, et al. Initial identification of a blood-based chromosome conformation signature for aiding in the diagnosis of amyotrophic lateral sclerosis. EBioMedicine 2018;33:169-184.

34. Jakub JW, Grotz TE, Jordan P, et al. A pilot study of chromosomal aberrations and epigenetic changes in peripheral blood samples to identify patients with melanoma. Melanoma Res 2015;25:406-411.

35. Carini C, Hunter E, Scottish Early Rheumatoid Arthritis Inception cohort I, et al. Chromosome conformation signatures define predictive markers of inadequate response to methotrexate in early rheumatoid arthritis. J Transl Med 2018;16:18

36. Yan H, Hunter E, Akoulitchev A, et al. Epigenetic chromatin conformation changes in peripheral blood can detect thyroid cancer. Surgery 2019;165:44-49.

37. Salter M, Powell R, Back J, et al. Genomic architecture differences at the HTT locus associated with symptomatic and pre-symptomatic cases of Huntington's disease in a pilot study. F1000Research 2019;7:1-23.

38. Crutchley JL, Wang XQ, Ferraiuolo MA, Dostie J. Chromatin conformation signatures: ideal human disease biomarkers?. Biomark Med 2010;4:611-629.

39. Salter M, Westra W, Elvidge W, et al. Chromosome conformation signatures as a clinical tool for diagnosis, prognosis and disease understanding in ALS. Poster presented at the ENCALS Annual Meeting; June 20-22, 2018; Oxford, United Kingdom.

40. Candia J, Cheung F, Kotliarov Y, et al. Assessment of variability in the SOMAscan assay. Sci Rep 2017;7:14248.

41. Hathout Y, Brody E, Clemens PR, et al. Large-scale serum protein biomarker discovery in Duchenne muscular dystrophy. Proc Natl Acad Sci USA 2015;112: 7153-7158.

42. Kiddle SJ, Steves CJ, Mehta M, et al. Plasma protein biomarkers of Alzheimer's disease endophenotypes in asymptomatic older twins: early cognitive decline and regional brain volumes. Transl Psychiatry 2015;5:e584.

43. Hathout Y, Conklin LS, Seol H, et al. Serum pharmacodynamic biomarkers for chronic corticosteroid treatment of children. Sci Rep 2016;6:31727. 


\title{
Neurology ${ }^{\circ}$ Clinical Practice
}

\author{
Radicava/Edaravone Findings in Biomarkers From Amyotrophic Lateral Sclerosis \\ (REFINE-ALS): Protocol and Study Design \\ James Berry, Benjamin Brooks, Angela Genge, et al. \\ Neurol Clin Pract 2021;11;e472-e479 Published Online before print September 23, 2020 \\ DOI 10.1212/CPJ.0000000000000968
}

This information is current as of September 23, 2020

$\begin{array}{ll}\begin{array}{l}\text { Updated Information \& } \\ \text { Services }\end{array} & \begin{array}{l}\text { including high resolution figures, can be found at: } \\ \text { http://cp.neurology.org/content/11/4/e472.full.html }\end{array} \\ \text { References } & \text { This article cites } 42 \text { articles, } 8 \text { of which you can access for free at: } \\ & \text { http://cp.neurology.org/content/11/4/e472.full.html\#\#ref-list-1 } \\ \text { Subspecialty Collections } & \text { This article, along with others on similar topics, appears in the } \\ & \text { following collection(s): } \\ & \text { All Clinical Neurology } \\ & \text { http://cp.neurology.org//cgi/collection/all_clinical_neurology } \\ & \text { All Clinical trials } \\ & \text { http://cp.neurology.org//cgi/collection/all_clinical_trials } \\ & \text { Amyotrophic lateral sclerosis } \\ & \text { http://cp.neurology.org//cgi/collection/amyotrophic_lateral_sclerosis_ } \\ & \text { Clinical trials Methodology/study design } \\ & \text { http://cp.neurology.org//cgi/collection/clinical_trials_methodology_stu } \\ & \text { dy_design_ } \\ & \text { Information about reproducing this article in parts (figures,tables) or in } \\ & \text { its entirety can be found online at: } \\ & \text { http://cp.neurology.org/misc/about.xhtml\#permissions } \\ \text { Permissions \& Licensing } & \text { Information about ordering reprints can be found online: } \\ & \text { http://cp.neurology.org/misc/addir.xhtml\#reprintsus }\end{array}$

Neurol Clin Pract is an official journal of the American Academy of Neurology. Published continuously since 2011, it is now a bimonthly with 6 issues per year. Copyright $\odot 2021$ The Author(s). Published by Wolters Kluwer Health, Inc. on behalf of the American Academy of Neurology.. All rights reserved. Print ISSN: 2163-0402. Online ISSN: 2163-0933.

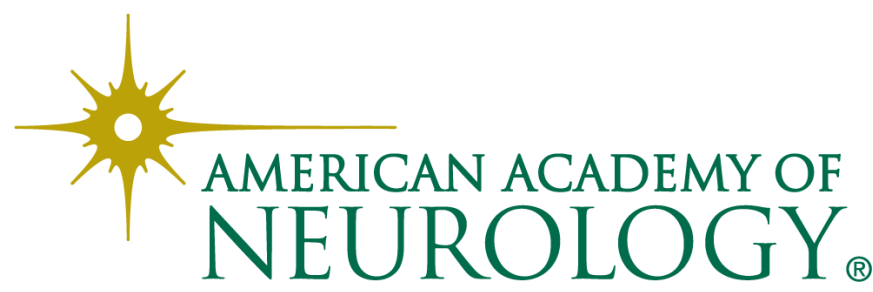

